\title{
Pulmonary function and complications following chemotherapy and stem cell support in breast cancer
}

\author{
F. Fanfulla*, P. Pedrazzoli*, G.A. Da Prada*, C. Bruschi\# ${ }^{\#}$ E. Dacosto, A. Zambelli*, \\ G.R. della Cuna*, C. Rampulla
}

Pulmonary function and complications following chemotherapy and stem cell support in breast cancer. F. Fanfulla, P. Pedrazzoli, G.A. Da Prada, C. Bruschi, E. Dacosto, A. Zambelli, G.R. della Cuna, C. Rampulla. (C)ERS Journals Ltd 2000.

ABSTRACT: Pulmonary complications are frequent in patients treated with highdose chemotherapy and autologous bone marrow transplantation for breast cancer or other solid tumours.

This study analyses the development of lung toxicity, changes in respiratory function and occurrence of clinical symptoms in a group of 24 patients (mean age $46 \pm 7 \mathrm{yrs}$ ) who underwent high-dose sequential chemotherapy (HDS) with autologous peripheral blood stem cell (PBSC) support for high risk breast cancer. Clinical examination, chest radiography and lung function tests were performed before the HDS and 1 and 3 months following transplantation.

Only one patient developed acute interstitial pulmonary disease which resolved after prednisone therapy. No patients developed infectious complications after transplantation. Baseline respiratory function was normal for most of the parameters. Only lung diffusing capacity of the lung for carbon monoxide $(T L, C O)$ and maximal inspiratory pressure were below the normal range. Following PBSC transplantation only one patient had an altered vital capacity while $72.3 \%$ of patients had reduced $T \mathrm{~L}, \mathrm{CO}$ values at 1 month and $54.5 \%$ at 3 months after transplantation. Maximal expiratory flow at $25 \%$ forced vital capacity, $T \mathrm{~L}, \mathrm{CO}$ and maximal expiratory pres-sure were significantly reduced after 1 month but recovered slightly by 3 months. Arterial oxygen tension between baseline and both follow-up evaluations declined significantly in patients seropositive for human cytomegalovirus.

It is concluded that this high-dose sequential chemotherapy regimen is acceptably safe since no pulmonary related mortality or respiratory infectious complications were observed. The only lung function alteration induced was an isolated diffusing capacity of the lung for carbon monoxide impairment, clinically negligible and partially recovered within 3 months.

Eur Respir J 2000; 15: 56-61.

High-dose, myeloablative, chemotherapy with autologous haematopoietic stem cell support is increasingly being used for the treatment of breast cancer (BC) in females at high risk of persistent or recurrent disease [1-6]. The use of megadoses of cytotoxic agents is associated with a variety of treatment-related side effects including severe bone marrow aplasia, mucositis and organ toxicity.

Pulmonary complications are frequent in patients receiving myeloablative treatment and autologous bone marrow transplantation (ABMT) [7]. These complications include chemotherapy-related lung toxicity, infectious or radiation pneumonitis, acute alveolar haemorrhage and development of lung functional abnormalities. Idiopathic pneumonia syndrome, i.e. diffuse lung injury without evidence of infection, is the most common serious pulmonary complication, occurring in $10-20 \%$ of all bone marrow (BM) transplant recipients. The changes in lung volumes or diffusing capacity of the lung for carbon monoxide $(T \mathrm{~L}, \mathrm{CO})$ appear to be strongly related to mortality [8]. Most of the data reported so far on pulmonary toxicity are, however, in the setting of BM transplantation. The autologous transfusion of progenitor cells, collected by leukaphereses from peripheral blood, is now
${ }^{\#}$ Respiratory Function Laboratory, IRCCS S. MaugeriFoundation, RehabilitationCentre of Montescano (Pavia, Italy) *Division of Medical Oncology, IRCCS S. Maugeri Foundation, Medical Centre of Pavia, Italy

Correspondence: F. Fanfulla

Laboratorio di Fisiopatologia Respiratoria Centro Medico di Montescano

27040 Montescano (Pavia)

Italy

Fax: 39038561386

Keywords: Bone marrow transplantation breast cancer

gas exchange

respiration

respiratory function

stem cell transplantation

Received: July 91998

Accepted after revision August 291999

Supported by the Colt Foundation. rapidly replacing autologous $\mathrm{BM}$ transplantation for haematopoietic support after high-dose chemotherapy (HDC) for malignancies $[9,10]$. The main reason for the success of the progenitor cell strategy is the capacity of peripheral blood stem cells (PBSC) to produce a much faster haematopoietic recovery than BM [11-13]. This means a reduced risk of haemorrhage and infection and less transplant-related mortality.

No prospective studies on pulmonary toxicity and respiratory function in patients with BC treated with HDC and PBSC support have been published in the literature. In the present study the authors report on the findings of a prospective analysis of respiratory function, pulmonary symptoms and complications in 24 patients undergoing high-dose sequential chemotherapy (HDS) and PBSC support for BC.

\section{Patients and methods}

\section{Patients}

Twenty-four consecutive BC patients (meanage $46 \pm 7$ yrs; body mass index (BMI) $24.9 \pm 4.3 \mathrm{~kg} \cdot \mathrm{m}^{-2}$ ) were given 
HDS and a circulating progenitor cell transplantation between September 1995 and September 1997 in the Division of Oncology, Medical Centre of Pavia, Italy. Chest clinical examination, chest radiography and lung function tests were performed before initiating the cytotoxic regimens and 1 and 3 months after transplantation. Respiratory symptoms occurring in the interval between the scheduled investigations were recorded and coded. Sixteen of the 24 patients $(66.6 \%)$ had positive serological evidence of human cytomegalovirus (HCMV) infection; 16 patients $(66.6 \%)$ were past-smokers. They had stopped smoking at least 1 month before the study and they did not change their smoking habit during the study.

Before entering the HDS programme, patients were categorized into two levels of risk for pulmonary toxicity (arbitrary scale) based on previous cytotoxic therapy: risk 0 (13 patients), no chemotherapy before entering the study; risk 1 (11 patients), neoadjuvant chemotherapy including three epirubicin doses $\left(120 \mathrm{mg} \cdot \mathrm{m}^{-2}\right)$. All patients had breast surgery $<1$ month before beginning the HDS. Eighteen had a mastectomy (Halsted's in two, Madden's in four, Patey's in 11) and six (25\%) had a quadrantectomy. No patients developed lung metastases during the study period.

Patients underwent HDS consisting of: cyclophosphamide $\left(\mathrm{CY} ; 7 \mathrm{~g} \cdot \mathrm{m}^{-2}\right.$ plus granulocyte colony-stimulating factor (G-CSF) support), high-dose methotrexate (MTX; 8 $\left.\mathrm{g} \cdot \mathrm{m}^{-2}\right)$ with leucovorin rescue plus vincristine $(1.5 \mathrm{mg}$. $\left.\mathrm{m}^{-2}\right)$, two epirubicin doses $\left(120 \mathrm{mg} \cdot \mathrm{m}^{-2}\right)$ and, as the final myeloablative regimen requiring stem cell support, thiotepa $\left(600 \mathrm{mg} \cdot \mathrm{m}^{-2}\right)$ and L-phenylalanine mustard (L-PAM) $\left(160 \mathrm{mg} \cdot \mathrm{m}^{-2}\right)$ [6]. This treatment entailed the administration of high doses of five different drugs within the shortest period possible compatible with avoiding haematological or nonhaematological toxicity.

Twenty-four hours after the completion of HDC more than $5 \times 10^{6} \mathrm{CD} 34+$ cells, previously collected and stored in liquid nitrogen, were reinfused into each patient [14]. GCSF $\left(5 \mu \mathrm{g} \cdot \mathrm{kg} \cdot \mathrm{day}^{-1}\right)$ was given to all patients from the day of PBSC infusion until complete neutrophil recovery. Patients were transfused with irradiated, leukocyte-free packed red cells and single donor platelets to maintain haemoglobin levels $>8 \mathrm{~g} \cdot \mathrm{dL}^{-1}$ and platelet counts $>20$ $\times 10^{9} \cdot \mathrm{L}^{-1}$. Side-effects were recorded according to World Health Organisation (WHO) criteria [15]. Three patients, all of whom had undergone quadrantectomy, received irradiation of the whole breast and tumour bed $(50+10$ Gy) following completion of the HDS programme.

\section{Respiratory symptoms and complications}

At each scheduled appointment the presence of cough and/or phlegm, dyspnoea at rest or during daily activities, wheezing and fever, not sufficiently indicative of a specific pathology, were recorded and coded. If acute bronchitis or pneumonia was diagnosed, respiratory function tests were delayed until at least 10 days after recovery. Acute bronchitis was defined as a clinically apparent acute episode of airway inflammation with cough and mucopurulent phlegm requiring treatment; pneumonia was defined as the occurrence of an acute pulmonary infection, with physical and radiographical signs of parenchymal thickening [16]. In these cases, cultures for bacterial, mycotic and viral agents from secretions obtained by deep coughing were performed.

\section{Pulmonary function tests}

Lung volumes were determined using a body-plethysmograph (Jaeger, Hochberg, Germany). Measurements were performed according to recommendations in European Respiratory Society statements [17]. The best of two slow vital capacity (VC) and best of three forced vital capacity (FVC) measurements were recorded. VC, FVC, forced expiratory volume in one second (FEV1), FEV1/ $\mathrm{VC}$ ratio, maximal expiratory flow at 50\% (MEF50) and $25 \%$ (MEF25) of FVC were calculated.

$T \mathrm{~L}, \mathrm{CO}$ was determined using the single-breath method (Biomedin, Padova, Italy) and corrected for haemoglobin concentration [18]. For TL,CO determination, patients were required to inspire until total lung capacity (TLC) and then, after holding their breath for $10 \mathrm{~s}$, perform a relatively slow expiration till residual volume (RV) was achieved. The same skilled operators were involved in performing functional tests throughout the study. Since the correction of $T \mathrm{~L}, \mathrm{CO}$ for alveolar volume did not influence the results of the analysis, only uncorrected $T \mathrm{~L}, \mathrm{CO}$ values are reported. Measurements were performed according to the American Thoracic Society recommendations [19]. As reference equations the authors used those proposed by the European Community for Steel and Coal [17]. According to the European Respiratory Society statements [17], the authors expressed the respiratory function data as SD score standardized residuals (actual result-predicted result/residual standard deviation) and defined them as pathological when $<-1.64$, corresponding to $<5$ th percentile.

Respiratory muscle strength was assessed by measuring maximal inspiratory and expiratory pressures (MIP and MEP, respectively) at the mouth, using a previously reported method; pressures were registered, respectively, at RV and TLC. The best value of three reproducible manoeuvres was considered [20].

Arterial blood-gases were analysed by an automated, computerized gas analyser (ABL 500, Radiometer, Copenhagen, Denmark) and compared to recent reference values for the middle aged [21].

\section{Data analysis and presentation}

Data were stored and analysed with the STATISTICA $/ \mathrm{w}$ (StatSoft Inc., Tulsa, OK, USA) and SAS/STAT version 6.08 (SAS Institute Inc., Cary, NC, USA) software packages. All the variables entered in the analyses were expressed as mean $\pm \mathrm{SD}$.

Repeated measures analysis of variance (ANOVA) was used to analyse changes in pulmonary function tests over time. Tukey honest statistical difference (HSD) test for unequal sample sizes (Spjotvoll \& Stoline test) and the Scheffe $^{\prime}$ test were used to compare differences between groups and within groups, respectively. ANOVA analyses were performed to evaluate the role of age, previous chemotherapeutic treatment, seropositivity to HCMV, baseline respiratory function and smoking habit on the trend of respiratory function after HDC and PBSC support. A pvalue $<0.05$ was considered statistically significant. 


\section{Results}

High-dose sequential chemotherapy and peripheral blood stem cell transplantation

All patients completed the treatment and respiratory function evaluations as planned. Following transplantation, the median numbers of days needed to reach an absolute neutrophil count of $0.5 \times 10^{9} \cdot \mathrm{L}^{-1}$ and a platelet count of $50 \times 10^{9} \cdot \mathrm{L}^{-1}$ were 9 (range 9-12) and 11 (range 10-15) days, respectively. No graft failure was observed.

Neutropenia and thrombocytopenia grade 4 were observed in all patients as was stomatitis and/or oesophagitis >grade 3 [15]. Fever $>38^{\circ} \mathrm{C}$ was seen in all patients: i.v. antibiotics were given routinely. The treatment overall was well tolerated, with the exception of post-transplant mucositis, which precluded food intake for $\sim 10$ days in the majority of patients. Intravenous morphine analgesia was used during this period.

\section{Respiratory symptoms and complications}

At baseline, no patients had respiratory symptoms. In particular, smokers did not show a clinical pattern of chronic bronchitis. No patients complained of dyspnoea during exercise. In the early phase following transplantation, two-thirds of patients developed cough and phlegm; no dyspnoea was recorded. In none of these patients was any culture or chest radiograph evidence of airway infection found. This complication is probably related to the severe mucositis (grade 3-4 according to WHO criteria) which occurs in most patients when high doses of alkylating agents are administered.

Soon after recovery from aplasia one patient developed acute interstitial pulmonary disease which rapidly resolved after empirical prednisone therapy [22]. One month after HDC and PBSC reinfusion, no patient had clinical or radiological signs of acute respiratory infections. No cases of acute or chronic respiratory disease were documented at 3 months after the transplantation.

\section{Baseline respiratory function}

Table 1 shows lung function results and haemoglobin concentrations. All the variables except TL,CO and MIP were within the normal ranges. Only two patients (one smoker) had abnormal FEV1 and FEV1/VC values associated with reduced maximal expiratory flow (MEF50 and MEF25) indicating mild obstructive disease. TL,CO values were reduced in $36 \%$ of patients. No patients showed increased values of carboxyhaemoglobin that could explain the TL,CO reduction. However, past-smokers had lower values of $T \mathrm{~L}, \mathrm{CO}$ than nonsmokers (past-smokers $1.65 \pm 0.66$ versus nonsmokers $-0.35 \pm 1.56$ ) and MEF50 (past-smokers $-0.75 \pm 0.84$ versus nonsmokers $0.14 \pm 1.06$ ) (ANOVA $p=0.03$ and $p=0.05$, respectively). Furthermore, the oxygen tension in arterial blood peripheral blood stem cell support $\left(\mathrm{Pa}_{\mathrm{a}} \mathrm{O}_{2}\right)$ was significantly lower in past-smokers $(-1.81 \pm 0.95)$ than in nonsmoking patients $(-0.66 \pm$ 1.19) (ANOVA $p=0.03$ ), and its mean value was outside the normal range.

Patients with risk 1 had lower values of VC $(0.41 \pm 1.1$ versus $1.25 \pm 0.82, \mathrm{p}<0.05)$, and MIP $(64.6 \pm 33.9$ versus $46.7 \pm 10.5, \mathrm{p}<0.05)$ and higher values of $\mathrm{FEV} 1 / \mathrm{VC}(0.5 \pm$ 1.14 versus $-0.44 \pm 1.11, \mathrm{p}<0.05)$ indicating the development of a mild restrictive defect. TL,CO values were lower in patients with higher risk although the difference was not statistically significant $(-1.17 \pm 1.3$ versus $-0.54 \pm 1.54$, $\mathrm{p}=\mathrm{NS})$.

\section{Trend of respiratory function after peripheral blood stem cell support}

Table 1 shows the trend of the respiratory function data from baseline to 1 and 3 months after HDC and PBSC support. Only one patient (the one who developed acute interstitial pneumonia syndrome) had abnormal VC, 1 and 3 months after transplantation. However, $72 \%$ of patients had reduced $T \mathrm{~L}, \mathrm{CO}$ values at 1 month and $54 \%$ at 3 months. No statistically significant changes in $\mathrm{VC}$, $\mathrm{FEV} 1 / \mathrm{VC}$ or FRC were observed between baseline and 1-3 months after PBSC transplant. In contrast, MEF25, $T \mathrm{~L}, \mathrm{CO}$ and MEP declined in a statistically significant way followed by a slight recovery 3 months following transplantation. The extent of this respiratory function decline was more evident for $T \mathrm{~L}, \mathrm{CO}$ (fig. 1).

Table 1. - Baseline, 1 and 3-months respiratory function data

\begin{tabular}{|c|c|c|c|c|}
\hline & Baseline & 1 month & 3 months & ANOVA $p$ \\
\hline $\mathrm{Hb} g \cdot \mathrm{dL}^{-1}$ & $11.8 \pm 1.52$ & $10.8 \pm 1.17^{\#}$ & $11.9 \pm 1.32^{\#}$ & 0.01 \\
\hline VC SD score & $0.87 \pm 1$ & $0.8 \pm 1.1$ & $0.8 \pm 1.18$ & NS \\
\hline FEV1 SD score & $0.5 \pm 0.83$ & $0.35 \pm 0.9$ & $0.23 \pm 0.9$ & 0.05 \\
\hline FEV1/VC SD score & $-0.01 \pm 1.2$ & $-0.07 \pm 1.2$ & $-0.17 \pm 1.2$ & NS \\
\hline FRC SD score & $0.15 \pm 0.64$ & $0.37 \pm 0.67$ & $0.42 \pm 0.77$ & NS \\
\hline TLC SD score & $0.36 \pm 0.69$ & $0.46 \pm 0.74$ & $0.45 \pm 0.87$ & NS \\
\hline TL,CO SD score & $-0.71 \pm 1.46^{+}$ & $-2.24 \pm 1.07^{+}$ & $-1.76 \pm 1.27^{+}$ & 0.000007 \\
\hline TL,CO \% pred. & $90.8 \pm 18.3$ & $72.6 \pm 13.2$ & $78.3 \pm 15.8$ & 0.000005 \\
\hline $\mathrm{Pa}, \mathrm{O}_{2} \mathrm{mmHg}$ & $-0.1 \pm 1.23$ & $-1.0 \pm 0.93$ & $-0.95 \pm 0.74$ & NS \\
\hline MIP $\mathrm{cmH}_{2} \mathrm{O}$ & $56.6 \pm 20.1$ & $55 \pm 15.5$ & $59.4 \pm 19.7$ & NS \\
\hline $\mathrm{MEP} \mathrm{cmH}_{2} \mathrm{O}$ & $86.7 \pm 22.6$ & $78.1 \pm 26.3$ & $91.6 \pm 33.7$ & 0.01 \\
\hline
\end{tabular}

Data are expressed as $\mathrm{SD} \pm$ score. Post hoc comparison: *: $\mathrm{p}=0.04 ;{ }^{*}: 1$ month versus 3 months, $\mathrm{p}<0.05 ;{ }^{+}$: baseline versus 1 month, $\mathrm{p}<0.01$, baseline versus 3 months $\mathrm{p}<0.01$. ANOVA: analysis of variance; Hb: haemoglobin; VC: vital capacity; SD score: standardized residuals (actual result - predicted result/residual standard deviation); FEV1: forced expiratory volume in one second; FRC: functional residual capacity; TLC: total lung capacity; $T \mathrm{~L}, \mathrm{CO}$ : diffusing capacity of the lung; $P \mathrm{a}, \mathrm{O}_{2}$ : oxygen tension in arterial blood; MIP: maximal inspiratory pressure; MEP: maximal expiratory pressure. $1 \mathrm{mmHg}=0.133 \mathrm{kPa}$. 


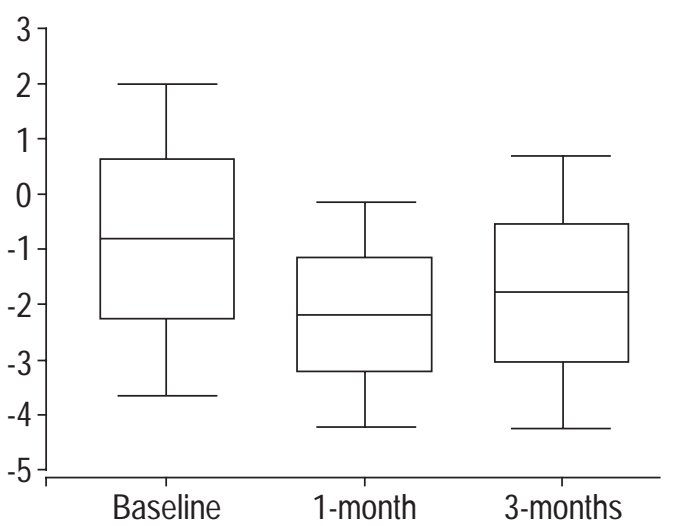

Fig. 1. - Trend of diffusing capacity of the lung for carbon dioxide $(T \mathrm{~L}, \mathrm{CO})$ values SD score; standardized residuals (actual result - predicted result/residual standard deviation) from baseline to 1 and 3 months follow-up. The error bars indicate $\pm 1.96 \mathrm{SD}$, the horizontal lines indicate the mean value, and the boxes indicate $\pm 1.00 \mathrm{SD}$.

A statistically significant correlation was found between $T \mathrm{~L}, \mathrm{CO}$ values and $\mathrm{Pa}, \mathrm{O}_{2}$ values (calculated as the difference between baseline and 1-month values): $\mathrm{r}=0.51$; $\mathrm{p}=0.02$. When only patients seropositive to HCMV were analysed the degree of correlation increased $(r=0.59 ; \mathrm{p}=0.04)$ while the correlation disappeared in the seronegative patients $(r=$ 0.07 ; $\mathrm{p}=\mathrm{NS}$ ).

The trend of TL,CO from baseline to the 3-month followup was significantly influenced by the baseline respiratory function (MANOVA $\mathrm{p}=0.04$ ). Patients with completely normal baseline respiratory function developed a significant decline of TL,CO by the 1-month evaluation but had a faster, more substantial recovery 3 months after HDS and PBSC support (baseline $-0.1 \pm 1.1 ; 1$ month $-1.8 \pm 0.9 ; 3$ months $-1.18 \pm 0.88 ; \mathrm{p}<0.05)$. In patients with abnormal baseline respiratory function, no recovery was observed 3 months after HDS and PBSC support (baseline -2.36 \pm 0.5 ; 1 month $-3.2 \pm 0.7 ; 3$ months $-3.1 \pm 1.1$ ).

HCMV seropositive patients had a statistically significant decline of $\mathrm{Pa}, \mathrm{O}_{2}$ (expressed as variations of $\mathrm{Pa}, \mathrm{O}_{2}$ $\mathrm{SD}$ score) between baseline and the 3-month follow-up (HCMV+ - $0.23 \pm 1$ versus HCMV- 0.72 \pm 0.9 ; ANOVA $\mathrm{p}<$ 0.05 ; fig. $2 \mathrm{a})$ and between the 1 -month and 3 -month evaluations $(\mathrm{HCMV}+-0.25 \pm 0.7$ versus $\mathrm{HCMV}-0.76 \pm 1.13$; ANOVA p<0.05) (fig. 2b).

The trends in respiratory function were not significantly influenced by the other factors considered: age and previous chemotherapy.

\section{Discussion}

The present study demonstrates that acute pulmonary toxicity occurs in a very low percentage (4\%) of high-risk $\mathrm{BC}$ patients undergoing HDC with PBSC support. In contrast, the great majority of patients developed a clinically silent decrease in TL,CO. An initial recovery of lung function impairment was documented 3 months after transplantation. Among the evaluated risk factors, baseline respiratory function and seropositivity to HCMV seemed to be the only determinants influencing the trend of respiratory function after this aggressive chemotherapy.
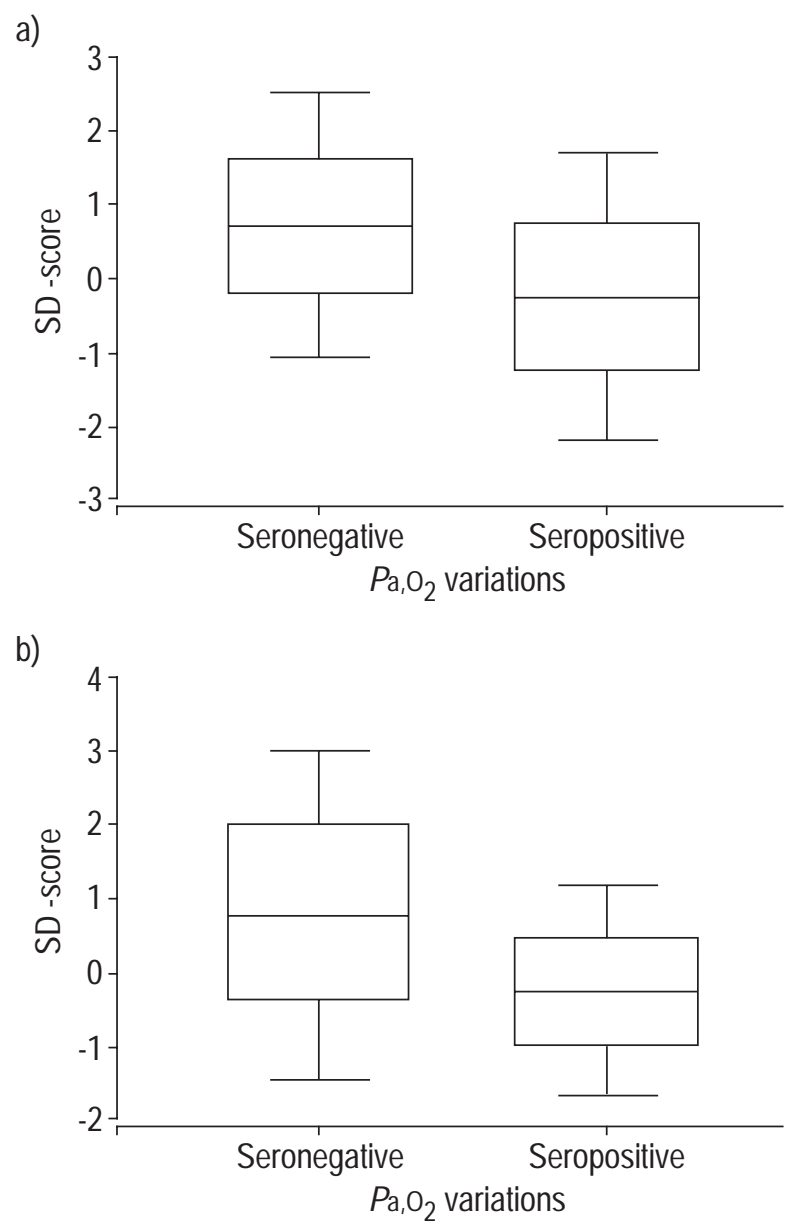

Fig. 2. - Variations of arterial oxygen tension $\left(\mathrm{Pa}_{\mathrm{a}} \mathrm{O}_{2}\right)$ (expressed as variation of $\mathrm{Pa}_{\mathrm{a}} \mathrm{O}_{2} \mathrm{SD}$ score; standardized residuals (actual result predicted result/residual standard deviation)) between a) baseline and the 3-month follow-up and b) the 1-month and 3-month follow-up in human cytomegalovirus (HCMV) seropositive and seronegative patients. The error bars indicate $\pm 1.96 \mathrm{sD}$, the horizontal lines indicate the mean values and the boxes indicate $1.00 \mathrm{SD}$.

HDC with autologous BM or PBSC transplantation is being increasingly employed as a component of adjuvant therapy for high-risk BC. In the setting of ABMT, pulmonary complications, including infections, idiopathic pneumonia syndrome and/or changes in pulmonary function, are significant sources of morbidity.

In a recent report, $4 \%$ of patients undergoing ABMT developed pneumonia; this complication occurred within 1 and 3 months in $50 \%$ and $67 \%$ of cases, respectively [23]. In another series, SEIDEN et al. [24] reported a high mortality rate in patients who developed pneumonia after ABMT. In the current study no respiratory infectious complications were documented either early following transplant or after discharge from hospital. This may well be related to the faster neutrophil engraftment occurring when PBSC instead of BM cells are transfused. The absence of busulphan from the chemotherapeutic agents included in the current study may also have played a role since this drug, especially in combination with CY, is strongly immunosuppressive [25].

Idiopathic pneumonia syndrome is the most serious pulmonary complication of ABMT occurring early after transplant in $10-20 \%$ of patients with a mortality rate of up to 
65\% [26]. CY and carmustine (1, 3-bis-(2-chloroethyl)-Lnitrosourea; $\mathrm{BNCU}$ ) are frequently used in combination at high doses in $\mathrm{BC}$ patients; nevertheless, while the negative effects of BCNU on lung are well documented [27-29], the role CY plays has not been so clearly demonstrated. SEIDEN et al. [24] compared the rate of pulmonary toxicity in patients with solid tumours who underwent four different HDC regimens (with ABMT support) and observed that interstitial pneumonia occurred in patients treated with BCNU/CY but not in patients receiving CY alone. However, WILCZYNSKI et al. [30] recently suggested that additional factors including the association with $\mathrm{CY}$, cisplatin or radiotherapy may predispose to BCNU-related lung toxicity and reported a much greater decline in $T \mathrm{~L}, \mathrm{CO}$ than the current authors found; in particular, $68 \%$ of their patients developed clinically significant restrictive lung defects within the first 3 months after transplantation which did not completely recover by the end of follow-up.

The difference between the results from the current study and those from other reports may be due to several factors. Firstly, the cytotoxic regimen did not include $\mathrm{BCNU}$ and local radiotherapy was given in a minority of cases [30]. CY was the only drug used, that has possible detrimental effects on the lung and this may explain the low percentage of functional abnormalities observed. It is unlikely that $\mathrm{CY}$ alone has a major role since the widely used myeloablative regimen developed by ANTMAN et al. [31] which includes CY, thiotepa and carboplatin, has been demonstrated to be devoid of significant lung toxicity.

Pre-existing lung damage has been reported to have a significant influence on the trend of lung function after BM transplantation [7], although this observation was not confirmed by WILCZINSKI et al. [30]. The current data are not easily comparable with those in previous reports because in most studies the patient population was heterogeneous, different myeloablative regimens were employed and the evaluation of pulmonary toxicity was retrospective. The current study was prospective, all patients enrolled had stage II/III BC and all received the same HDS regimen in an adjuvant setting.

The only negative effect on respiratory function that was found was a lower extent of TL,CO recovery within the first 3 months after PBSC in patients with baseline respiratory function impairment. Similar results were reported by LuND et al. [32] in patients who underwent BM transplantation following a high-dose busulphan/CY conditioning regimen; LuND et al. [32] also observed a reduction in lung volumes which mainly occurred 3 months after BM transplantation, and was partially explained by extrapulmonary factors such as muscular weakness. The current authors, however, did not find any change in maximal inspiratory pressure in their patients either at 1 or 3 months after PBSC.

The detrimental effect of HCMV seropositivity on gas exchange in the patients was quite unexpected. Reactivation of cytomegalovirus (CMV) is a major cause of morbidity and mortality following allogeneic BM transplantation, and is probably related to development of acute graft-versus-host disease (GvHD); the risk of developing HCMV pneumonia is significantly less in an autologous setting [33]. The negative effect of HCMV might be due to a clinically silent reactivation of the CMV infection producing minimal lung damages with respiratory function impairment [34, 35]. Indeed, STALs et al. [35] showed that in rats receiving an allogeneic BM transplantation, CMV induced lung microvascular damage resulting in interstitial lung disease, independently of GvHD development.

In conclusion, the patients who received HDS and PBSC support did not suffer pulmonary related-mortality or pulmonary infectious complications but developed a minimal lung function impairment (isolated TL,CO impairment) without clinical symptoms. It is worth noting that the chemotherapic regimen used has been demonstrated to improve disease-free and overall survival in $\mathrm{BC}$ and lymphoma patients as compared to conventional chemotherapy $[6,36]$, results which have yet to be proven for other more toxic regimens [30].

The relatively small number of patients studied could have influenced the results and evaluation on a larger number of patients is underway. Furthermore, longer follow-up is needed to assess the evolution of pulmonary function. Nevertheless, these preliminary positive results seem to confirm the reliability of this therapeutic approach in terms of lack of respiratory complications.

\section{References}

1. Peters WP, Shepall EJ, Jones RB, et al. High-dose combination alkylating agents with bone marrow support as initial treatment for metastatic breast cancer. J Clin Oncol 1988; 6: 1368-1376.

2. Bezwoda WR, Seymour L, Dansey RD. High-dose chemotherapy with hematopoietic rescue as primary treatment for metastatic breast cancer: a randomized trial. $J$ Clin Oncol 1995; 13: 2483-2489.

3. Peters WP, Jones RB, Vredenburgh J, et al. A large prospective randomized trial of high-dose combination alkylating agents (CPB) with autologous cellular support (ABMS) as consolidation for patients with metastatic breast cancer achieving complete remission after intensive doxorubicinbased induction therapy (AFM). J Clin Oncol 1996; 14 (Suppl. 1): 141.

4. Norton L. Evolving concepts in the systemic drug therapy of breast cancer. Sem Oncol 1997; 24 (Suppl. 2): 3-10.

5. Antman KH, Rowlings PA, Vaughan WP, et al. High-dose chemotherapy with autologous hematopoietic stem-cell support for breast cancer in north America. J Clin Oncol 1997; 15: 1870-1879.

6. Gianni AM, Siena S, Bregni M, et al. Efficacy, toxicity, and applicability of high-dose sequential chemotherapy as adjuvant treatment in operable breast cancer with 10 or more involved axillary nodes: five-year results. $J$ Clin Oncol 1997; 15: 2312-2321.

7. Quabeck K. The lung as critical organ in marrow transplantation. Bone Marrow Transplant 1994; 14: S19-S28.

8. Crawford SW, Pepe M, Lin D, Benedetti F, Deeg HJ. Abnormalities of pulmonary function tests after marrow transplantation predict non relapse mortality. Am J Respir Crit Care Med 1995; 152: 690-695.

9. Gianni AM. Where do we stand with the use of peripheral blood progenitor cells? Ann Oncol 1994; 5: 781-784.

10. To LB, Hailock DN, Simmons PJ, Jutter CA. The biology and clinical uses of blood stem cells. Blood 1997; 89: 2233-2258

11. Siena S, Bregni M, Di Nicola M, et al. Durability of hematopoiesis following autografting with peripheral 
blood hematopoietic progenitors. Ann Oncol 1994; 5: 935-941.

12. Schmitz N, Linch DC, Dreger P, et al. Randomized trial of filgrastim-mobilized peripheral blood progenitor cell transplantation versus autologous bone-marrow transplantation in lymphoma patients. Lancet 1996; 347: 353357.

13. Gratwohl A, Hermans J, Baldomero $\mathrm{H}$, et al. Blood and marrow transplantation activity in Europe 1995. European Group for Blood and Marrow Transplantation. Bone Marrow Transplant 1997; 19: 407-419.

14. Bender JG, To LB, Williams S, Schwartzberg LS. Defining a therapeutic dose of peripheral blood stem cells. $J$ Hematother 1992; 1: 329-341.

15. Miller AB, Hoogstraten B, Staquet M, Winkler A. Reporting results of cancer treatment. Cancer 1981; 47: 207-214.

16. Fanfulla F, Locatelli F, Zoia MC, et al. Pulmonary complications and respiratory function changes after bone marrow transplantation in children. Eur Respir J 1997; 10: 2301-2306.

17. Quanjer PhH, Tammeling GJ, Cotes JE, Pedersen OF, Peslin R, Yernault J-C. Report Working Party. Standardization of lung function tests. Eur Respir J 1993; 6 (Suppl. 16): 5-40.

18. Cotes JE. Lung Function. 5th Edn. Oxford, UK. Blackwell Scientific Publications, 1993.

19. American Thoracic Society. Single-breath carbon monoxide diffusing capacity (transfer factor). Am J Crit Care Med 1995; 152: 2185-2198.

20. Bruschi C, Cerveri I, Zoia MC, et al. Reference values of maximal respiratory mouth pressures: a population based study. Am Rev Respir Dis 1992; 146: 790-793.

21. Cerveri I, Zoia MC, Fanfulla F, et al. Reference values of arterial oxygen tension in the middle-aged and elderly. Am J Respir Crit Care Med 1995; 152: 934-941.

22. Kalaycioglu M, Kavuru M, Tauson L, Bolwell B. Empiric prednisone therapy for pulmonary toxic reaction after high-dose chemotherapy containing carmustine (BCNU). Chest 1995; 107: 482-487.

23. Gentile G, Micozzi A, Girmenia C, et al. Pneumonia in allogeneic and autologous bone marrow recipients. Chest 1993; 104: 371-375.

24. Seiden MV, Elias A, Ayash L, et al. Pulmonary toxicity associated with high-dose chemotherapy in the treatment of solid tumors with autologous marrow transplant: an analysis of four chemotherapy regimens. Bone Marrow Transplant 1992; 10: 57-63.

25. Roberts MM, To LB, Gillis D. Immune reconstitution following peripheral blood stem cell transplantation, auto- logous bone marrow transplantation and allogeneic bone marrow transplantation. Bone Marrow Transplant 1993; 12: 469-475.

26. Cherniack RM, Abrams J, Kalica AR. Pulmonary disease associated with breast cancer therapy. Am J Respir Crit Care Med 1994; 150: 1169-1173.

27. Todd NW, Peters WP, Ost AH, Roggli Vl, Piantadosi CA. Pulmonary drug toxicity in patients with primary breast cancer treated with high-dose chemotherapy and autologous marrow transplantation. Am Rev Respir Dis 1993; 147: 1264-1270.

28. Litam JP, Dail DH, Spitzer G, et al. Early pulmonary toxicity after administration of high-dose BCNU. Cancer Treat Rep 1981; 65: 39-44.

29. Cooper JAD, White DA, Matthay RA. Drug-induced pulmonary disease. Part 1: cytotoxic drugs. Am Rev Respir Dis 1986; 133: 321-340.

30. Wilczynski SW, Erasmus JJ, Petros WP, Vredenburgh JJ, Folz RJ. Delayed pulmonary toxicity syndrome following high-dose chemotherapy and bone marrow transplantation for breast cancer. Am J Respir Crit Care Med 1998; 157: 565-573.

31. Antman K, Ayash L, Elias A, et al. A phase II study of high-dose cyclophosphamide, thiotepa and carboplatin with autologous marrow support in women with measurable advanced breast cancer responding to standarddose chemotherapy. J Clin Oncol 1992; 10: 102-110.

32. Lund MB, Kongerud J, Brinch L, Evensen SA, Boe J. Decreased lung function in one year survivors of allogeneic bone marrow transplantation conditioned with high-dose busulfan and cyclophoshamide. Eur Respir $J$ 1995; 8: 1269-1274.

33. Clark JG, Hansen JA, Hertz MI, Parkman R, Jensen L, Peavy HH. Idiopathic pneumonia syndrome after bone marrow transplantation. NHLI workshop summary. $\mathrm{Am}$ Rev Respir Dis 1993; 147: 1601-1606.

34. Couriel D, Canosa J, Engler H, Collins A, Dunbar C, Barrett AJ. Early activation of cytomegalovirus and high risk of interstitial pneumonitis following T-depleted BMT for adults with hematological malignancies. Bone Marrow Transplant 1996; 18: 347-353.

35. Stals FS, Steinhoff G, Wagenaar SS, et al. Cytomegalovirus induces interstitial lung disease in allogeneic bone marrow transplant recipient rats independent of acute graft-versus-host response. Laboratory Investigation 1996; 74: 343-352.

36. Gianni AM, Bregni M, Siena S, et al. High-dose chemotherapy and autologous bone marrow transplantation compared with MACOP-B in aggressive B-cell lymphoma. N Engl J Med 1997; 336: 1290-1297. 